\title{
Al participar se hace ciudad en el entretanto. Urbanismo emergente en Bilbao*
}

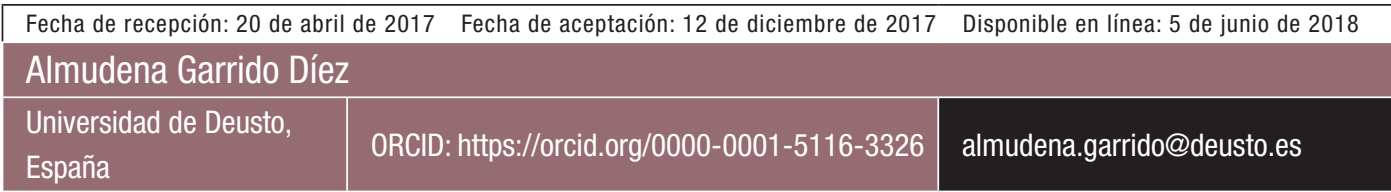

Resumen Durante las tres últimas décadas se ha llevado a cabo un urbanismo definido por megaproyectos y una planificación top-down sin participación real de la ciudadanía. Con el objetivo de investigar el papel de esta última en la transformación del espacio público y en la reconstrucción de las relaciones sociales, se analiza un proceso de participación de un movimiento social urbano en la península de Zorrotzaurre, Bilbao, a lo largo de una década (2004-2014). Mediante la metodología investigación-acción y técnicas cualitativas como la narrativa longitudinal (2004- 2016) y multicapa (actores institucionales, económicos y sociales) en la primera fase y entrevistas semiestructuradas en la segunda, descubrimos que es ardua la tarea de construir espacios de poder deliberativos para la ciudadanía y que es en los nuevos espacios de encuentro creados por un aprendizaje social en donde puede surgir un cambio de paradigma en la construcción de nuestras ciudades.

Palabras clave planificación urbana; participación ciudadana; aprendizaje social; democracia participativa; movimientos sociales 


\section{In the Meantime, Participation Makes the City. Emerging Urbanism (Bilbao)}

Abstract During the last three decades, an urbanism defined by megaprojects and top-down planning has been carried out without the real participation of citizens. With the objective of investigating the role played by citizens in the transformation of public space and in the reconstruction of social relations, we analyse process of participation of an urban social movement in the Zorrotzaurre Peninsula, Bilbao, over a decade (2004-2014). Using the research-action methodology and qualitative techniques such as the longitudinal and multilayer narrative (institutional, economic and social actors) in a first phase, and semi-structured interviews in a second, we discover that the task of building spaces of deliberative power is arduous for the citizens, and that it is through the new meeting spaces created by social learning that a paradigm shift in the construction of our cities can arise.

Keywords urban planning; citizen participation; social learning; participatory democracy; social movements

\section{Participando, a cidade é feita na mais ambada. Urbanismo emergente em Bilbao}

Resumo Durante as últimas três décadas, um urbanismo definido por megaproyectos e planejamento de cima para baixo foi realizado sem a participação real dos cidadáos. Com o objetivo de investigar o papel desempenhado pelos cidadãos na transformaçáo do espaço público e na reconstrução das relaçóes sociais, um processo de participaçáo de um movimento social urbano na península de Zorrotzaurre, em Bilbao, é analisado ao longo de um década (2004-2014). Usando a metodologia de pesquisa-ação e técnicas qualitativas, como a narrativa longitudinal (2004-2016) e multicamadas (atores institucionais, econômicos e sociais) em uma primeira fase e entrevistas semi-estruturadas em um segundo, descobrimos que a tarefa de construir espaços de poder é árdua deliberativo para a cidadania e que é através dos novos espaços de encontro criados por uma aprendizagem social que uma mudança de paradigma na construção de nossas cidades pode surgir.

Palavras chave planejamento urbano; participação cidadã; aprendizagem social; democracia participativa; movimentos sociais 


\section{Introducción}

Vivimos y convivimos en ciudades que han sido tomadas por los intereses del capital y han dejado de pertenecer a la gente. Esta forma de urbanismo empresarial ha sido abordada por un amplio grupo de autores que otorgan protagonismo a las personas en los espacios de vida colectiva (Zukin, 1988; Harvey, 1989; Sassen, 2000; Soja; 2008; Jacobs; 1961; Gehl, 2010). Lefebvre (1969) y Harvey (2013) además reivindicaban el derecho a la ciudad y una ciudadanía como protagonista y motor del cambio. A esto se añade otra mirada: una planificación colaborativa y los debates sobre gobernanza, en concreto, el protagonismo de la participación en la gestión de la ciudad (Healey, 1997; 2006; Innes 1995; Forester, 1988).

La ciudad es un asunto complejo que puede ser asumido desde distintos puntos de vista. Lo que aquí se propone es centrarse en dos líneas de investigación: a) la reconstrucción de espacios y la resignificación de las relaciones sociales, y b) la fundamentación de medidas de gobernanza dentro del marco urbano.

Se desarrolló un estudio etnográfico longitudinal sobre la península de Zorrotzaurre en Bilbao, un barrio degradado y olvidado por la Administración durante más de tres décadas, donde habita una comunidad pequeña que trata de mantener su identidad y demanda el derecho a participar en la gestión del espacio público, el derecho a la ciudad. En 2004 surgió el Foro para un Zorrotzaurre sostenible, un movimiento social urbano que, en un espacio de diálogo, propuso futuros alternativos a la forma de hacer ciudad. Doce años después se ha generado un gran número de iniciativas bottom-up en el entretanto de su regeneración oficial, como un proceso de construcción colectiva.

En primer lugar, este artículo revisa el estado actual de los debates teóricos pilares de la investigación: la ciudad en el contexto de regeneración de las ciudades posindustriales, el concepto de derecho a la ciudad y la planificación colectiva. El segundo apartado aborda el caso de estudio: la historia de un proceso de participación de un movimiento social en un barrio con fuerte identidad local, que demanda participar en el diseño de su barrio por no sentirse representado. Exploramos las dinámicas internas y externas del movimiento y el aprendizaje y las prácticas sociales generadas para caminar hacia ciudades más consensuadas y más habitables. La tercera parte recoge los resultados de la movilización y el impacto de la participación ciudadana en la planificación de la ciudad. Con esta información se propone un camino hacia la ciudad proactiva y se recogen las directrices de un acto de participación acción que podría aplicarse en otros contextos urbanos.

\section{Metodología}

Se abordó la investigación a partir del trabajo empírico que la autora ha adelantado durante más de una década con la metodología investigación-acción, es decir, con la reflexión colectiva de los sujetos de la investigación. Las herramientas seleccionadas adaptadas al contexto sociourbano correspondieron al modelo cualitativo. 
Se comenzó con la revisión bibliográfica y el análisis de un proceso de participación bottom up con un enfoque interpretativo-critico mediante la técnica historia de vida de un movimiento social, observación participante y recolección de testimonios en conversaciones informales, para hacer un microexamen de los imaginarios simbólicos de las personas que participan en el diseño de la ciudad.

Con el análisis de la narrativa se determinaron dos cuestiones clave en esta investigación: por un lado, los detonantes del surgimiento de un movimiento social en el espacio urbano y, por otro, el protagonismo de la participación en la gestión de la ciudad. En la segunda fase, en 2015, se hicieron dieciséis entrevistas semiestructuradas para observar el impacto de la participación y lo ocurrido en el entretanto de la regeneración urbana, o sea, los nuevos espacios de diálogo, los nuevos usos de espacio urbano y las nuevas relaciones sociales; en definitiva, el impacto que ha tenido el aprendizaje social en la ciudad. Estas cuestiones nos ayudan a reflexionar sobre los resultados de la participación, a definir los ingredientes para que sea efectiva y a construir mejores ciudades.

\section{Del urbanismo neoliberal al derecho a la ciudad}

\section{Urbanismo empresarial}

La transformación de la ciudad enmarcada en un urbanismo con la lógica del mercado ha recrudecido la problemática urbana. Partimos de un proceso que comenzó en la década del sesenta en los países occidentales y dura hasta la actualidad. Los barrios se han ido definiendo por una globalización caracterizada por el capitalismo financiero volátil y especulativo que concentra la riqueza y ha creado el binomio centro-periferia, con núcleos y zonas dispersas, fragmentadas y segregadoras (Harvey, 1989; Borja, 2012). En este binomio, el automóvil se convirtió a mediados del siglo pasado en el rey del espacio público, con gran incremento en infraestructura para su uso.

Bajo la careta de mantener el Estado de bienestar, los Gobiernos de las ciudades que tienen que competir para seguir alimentando la voracidad del capital se esfuerzan por atraer inversores y planifican proyectos urbanos con arquitectos de renombre e infraestructuras culturales y turísticas como parte del mercadeo urbano (Ashworth y Voogd, 1990). Se recuperan y relanzan espacios industriales en desuso que se convertirán en espacios deseables para vivir y para innovar (Zukin, 1989). Sin embargo, detrás de estas políticas se esconde un incremento del valor del suelo. La acumulación de capital se vuelca hacia inversiones en la producción de espacios urbanos que luego se transforman en la estructura de clases (Harvey, 2013).

Esta forma de hacer ciudad acentúa la polarización de la sociedad y aumenta la pobreza, al crear barrios segregados con poco contacto entre personas de diferente estatus económico y social. En estas ciudades modernas, diseñadas y cosidas con el mismo patrón, además de una mayor desigualdad social, existen altos niveles de consumo de energía y suelos (Girardet, 1999), un incremento de los efectos del cambio climático (Klein, 2015) y una reducción de la calidad de vida de sus ciudadanos. A esto se han sumado cambios tecnológicos con impacto en la ciudad debido a los nuevos modos de información y comunicación, cambios socioculturales con la multiplicación de colectivos humanos muy heterogéneos (migraciones) y la individualización de los comportamientos.

Jacobs (1961) planteó una fuerte crítica a las políticas de renovación urbanística de la década del cincuenta que destruían comunidades y creaban 
espacios urbanos aislados y antinaturales. Las ideas de Le Corbusier recogidas en la Carta de Atenas llenaron los centros de la ciudad con edificios altos y separados y de tráfico creciente que domina el espacio público e impide que la gente se implique en la vida pública. Lugares como la plaza, la calle concurrida, el local de víveres y los parques próximos han ido desapareciendo y con ellos la interacción de las personas y un sentido de tolerancia, conciencia, identidad y respeto mutuo.

\section{Derecho a la ciudad y participación ciudadana}

Se reclama un cambio en la forma de construir la ciudad. Está ganando fuerza el concepto del "derecho a la ciudad" como paraguas que articula las luchas sociales democratizadoras. Los colectivos ciudadanos se levantan para hacer frente a los retos que plantea la globalización desde el ámbito municipal nacional e internacional ${ }^{1}$, es decir, cambia el paradigma de la ciudad-negocio al de la ciudad-derecho (Borja, 2012).

Este artículo está guiado por la importancia de incluir a las personas en la agenda de la planificación urbana y considerar las necesidades de la gente que vive y usa la ciudad. Esto implica "reclamar el derecho que nos da la libertad para rehacer nuestras ciudades y a nosotros mismos" (Lefebvre, 1969, p. 138) y reorientar el diseño de la ciudad hacia espacios públicos que posibiliten y refuercen el sentimiento de comunidad (Gehl, 2010) y, en este sentido, el derecho a la ciudad y la producción de espacios consistiría en repensar un escenario que "posibilite la distribución equitativa de los recursos, la humanización de los espacios en los que vivimos y la autogestión de los procesos" (Harvey, 2013, p. 20).
Podemos afirmar que la materialización del derecho a la ciudad ocurre con la inclusión de la ciudadanía en el diseño y la planificación de la ciudad, esto es, con la posibilidad de que cualquier persona pueda participar en los asuntos públicos de su comunidad. La democracia participativa aporta un modelo alternativo para gestionar los asuntos públicos (Pindado, 2005). Con este formato se prevé un espacio en donde la ciudadanía, el personal técnico y la clase política intervengan desde la corresponsabilidad en el proceso de elaboración de políticas y tengan en consideración las funciones de cada agente implicado. Esta es la gobernanza colaborativa: un proceso de toma de decisiones colectiva que es formal, por un consenso orientado y deliberativo, que pretende hacer o aplicar la política pública (Ansell y Gash, 2008). En este contexto, entendemos la participación como un derecho de la ciudadanía a incidir como protagonista en la toma de decisiones, la planificación y la gestión de asuntos público. Es la participación como un instrumento de democracia directa que enriquece y complementa la democracia representativa.

\begin{tabular}{|l|l}
\begin{tabular}{l} 
Tabla 1. Modelo participativo \\
\multicolumn{1}{c|}{ Modelos de democracia }
\end{tabular} & \multicolumn{1}{c}{ Eje y Actuaciones } \\
\hline Democracia representativa & $\begin{array}{l}\text { Eligiendo intermedios } \\
\text { Representación y control, } \\
\text { rendición de cuentas y } \\
\text { transparencia }\end{array}$ \\
\hline Democracia participativa / & $\begin{array}{l}\text { Incidiendo, influyendo, } \\
\text { discutiendo, colaborando } \\
\text { Gobernanza colaborativa }\end{array}$ \\
$\begin{array}{l}\text { Procesos participativos de } \\
\text { debate público. Colaboración } \\
\text { con iniciativas de la sociedad } \\
\text { civil }\end{array}$ \\
\hline Democracia directa & $\begin{array}{l}\text { Decidiendo directamente } \\
\text { Referendum, plebiscito, } \\
\text { iniciativa popular decisoria }\end{array}$ \\
\hline
\end{tabular}

Fuente: elaboración propia, con base en Pindado (2005)

En la literatura anglosajona existe un gran debate acerca de cómo deben ser estos procesos de

Por ejemplo, en el ámbito local están apareciendo nuevos modelos de desarrollo adaptados a los límites del planeta (movimiento de transición o la ocupación de espacios autogestionados para ejecutar diversas actividades por colectivos ciudadanos, como la plaza ocupada o Campo de Cebada en Madrid). En el escenario nacional sobresale la Plataforma de Afectados por la Hipoteca (PAH), un colectivo para detener los desalojos y en el internacional, Occupy, un movimiento sociopolítico contra la desigualdad social y la falta de democracia real en todo el mundo. 
participación. Encontramos las aportaciones de los autores que defienden un planeamiento más comunicativo y colaborativo que fundamentan su perspectiva en la teoría de la acción comunicativa de Habermas (1989) y en la teoría de la estructuración de Giddens (1984). Estas aproximaciones ponen el acento en el intercambio, el diálogo, el aprendizaje mutuo mediante la acción y la posibilidad de llegar a consensos racionales. Creen que en la propia reflexividad de los agentes sobre las asunciones y estructuras preestablecidas, a menudo injustas, está el potencial de transformarlas. Entre estos resaltan los trabajos de Forester (1988), Healey (1997; 2006) e Innes (1995).

\section{En el contexto de Bilbao, Zorrotzaurre en el entretanto}

\section{La transformación de Bilbao}

En este contexto teórico de urbanismo empresarial, el actual estudio revisa el modelo de regeneración urbana del Bilbao metropolitano que comenzó a finales de la década del ochenta. Este cambio de imagen, presentado como el paradigma del éxito en la reconversión de viejas ciudades industriales en ciudades culturales y turísticas, se articula en torno a tres elementos: a) aprovechamiento de los espacios de oportunidad creados por los terrenos liberados en los márgenes de la ría, como Abandoibarra o Zorrotzaurre; b) el planeamiento estratégico con megaproyectos y grandes infraestructuras, entre ellas, el saneamiento de la ría, el metro o el aeropuerto, y c) la adaptación de un esquema de gestión competitiva desarrollada a partir de la concertación interinstitucional.

La transformación urbana contó con gran reconocimiento del exterior que se tradujo, entre otros, en la concesión de premios en foros internacionales de prestigio como Bilbao Premio ciudades del mundo LKY, 2010 (Figura 1). Sin embargo, en el escenario interno se generó cierta crítica: por un lado, se había conseguido atraer atención internacional y turistas, pero no se implementaron actividades que impulsaran el necesario crecimiento económico (Esteban, 2000); por otro, con el fin de posicionarse como urbe global, atractiva y competitiva, se destinó gran cantidad de dinero público en determinadas zonas de la ciudad (espacios centrales y riberas urbanas) y se aumentaron los precios del suelo (Rodríguez, Vicario y Martínez, 2005). Esto produjo un impacto espacial y social desigual en la ciudad, por lo que se relegó a los barrios periféricos. Para gestionar la regeneración se crearon entidades público-privadas que permitieran la entrada de inversores privados en busca de rentabilidad económica, pero con el apoyo de recursos públicos.

En la cresta de la bonanza económica, en 2002, se firmó un acuerdo para la revitalización de la siguiente zona de oportunidad: Zorrotzaurre. Los poderes públicos y económicos fundaron una organización semipública y se contrató a una arquitecta de renombre para desarrollar el megaproyecto de firma como imán infalible de atención, turismo e inversión. Así comenzó la

Figura 1. Transformación urbanística de Abandoibarra, Bilbao

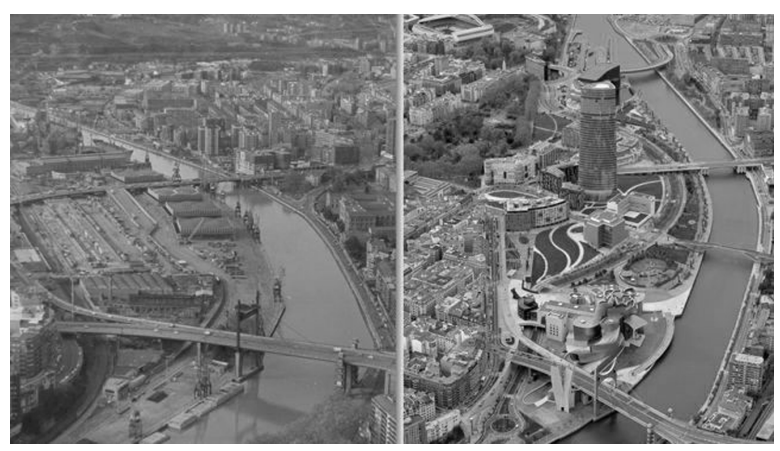

Fuente: Areso (2016) 
segunda regeneración urbana que llevaría a Bilbao a definir nodos para el desarrollo de la nueva economía creativa.

Esta forma de crear ciudad, en la cual la planificación se reduce a un simple mecanismo determinista, hace que se prescinda de toda participación ciudadana. El Ayuntamiento de Bilbao, pionero en el Estado espańol en dar $\mathrm{voz}^{2}$, aunque no voto, a asociaciones y entidades ciudadanas, ha mantenido unos patrones de relación con los movimientos sociales que no han variado mucho en la última década. Las decisiones relacionadas con el modelo de ciudad se cerraron a cualquier participación. Ante esta falta de escenarios, la ciudadanía abrió un espacio de debate y esta es la siguiente historia: un movimiento social urbano que propuso un proceso participativo en el marco de una ciudad en la que se ejerce el urbanismo empresarial (Rodríguez et al., 2005) basado en la competencia y los proyectos espectaculares. Esto origina una narrativa conectada con la pugna, lo que aleja la idea de ciudad en donde debe primar en el espacio urbano, el interés público y la participación.

\section{Historia de un movimiento social urbano. Foro para un Zorrotzaurre sostenible}

El análisis comienza con la historia de un movimiento social urbano que surge como respuesta al modelo de crecimiento productivista, con el objetivo de abrir espacios de diálogo y compartir futuros alternativos para el barrio, en contra de un urbanismo neoliberal programado. El lugar, la península de Zorrotzaurre, situada a las orillas del río Nervión. En esta aldea del centro de la ciudad conviven en la actualidad medio millar de vecinos, con sus preocupaciones del día a día y sus diferentes visiones de futuro, con pabellones industriales en ruinas con grafitis al aire libre y una vida salvaje de flora y fauna que se abre paso entre escombros. Hace solo un siglo, este barrio era una zona industrial con intensa actividad naval que puso a Bilbao en el mapa mundial del comercio y la actividad exportadora (Figura 2).

Figura 2. La península de Zorrotzaurre en 2004

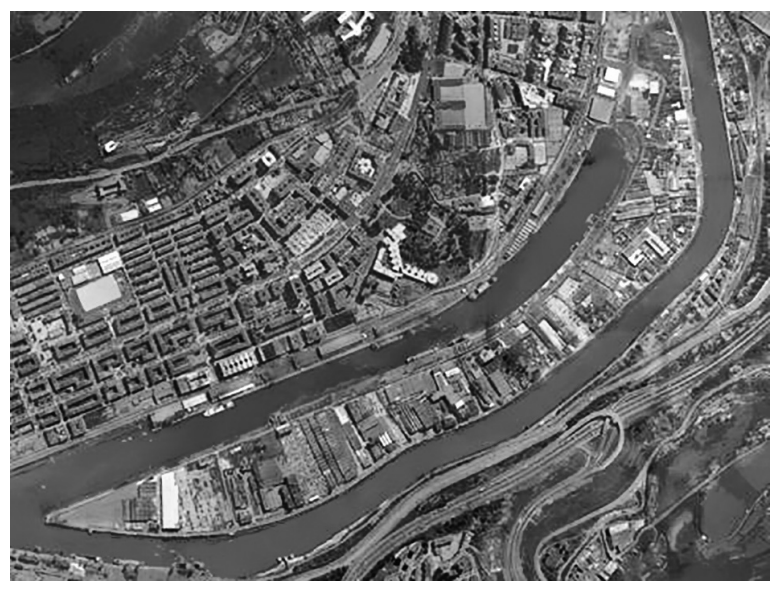

Fuente: Diputación Foral de Bizkaia

Con la crisis industrial en la década del setenta, en los márgenes de la ría fueron aumentando los pabellones arruinados y las estructuras abandonadas. Los comercios y servicios de la zona se iban cerrando. Las viviendas no se arreglaban esperando a que la Administración decidiera qué hacer en el barrio. No se invertía en el lugar. Creció una memoria centrada en el abandono institucional y en la marginación con respecto a otros barrios bilbaínos. "Se condenó a la ribera a la marginación y a un olvido que ha padecido durante más de medio siglo", escribía Mazin, periodista y vecino del lugar. "Aunque lo del olvido es un decir; se acuerdan de nosotros cada vez que algo ha molestado en el centro de Bilbao, el depósito de coches, el aparcamiento de camiones, los autobuses de Bilbobús, macrodiscotecas" (Mazin, 2001, p. 19). Así comenzamos el nuevo siglo, cuando los vecinos empezaron a oír rumores de que su barrio iba a ser planificado y tal vez demolido. Se creó un grupo gestor semipúblico para decidir el futuro urbanístico del lugar.

Ante el inminente desarrollo de la zona y la falta de información, la mayor parte de los vecinos 
miraba al futuro con temor e incertidumbre. Otros veían una oportunidad para crear una ciudad diferente. "No solo queríamos presentar críticas contra un sistema radicalmente insostenible, sino buscar soluciones a nivel local”, comenta Robert Alcock, vecino del barrio y uno de los promotores del Foro para un Zorrotzaurre sostenible.

Propusieron un espacio de debate. La primera reunión del Foro duró dos días de marzo de 2004, acudieron 150 personas entre políticos, expertos, vecinos, empresarios y hasta un representante del equipo de Zaha Hadid. Expresaron una gran diversidad de opiniones sobre Zorrotzaurre y su futuro, cuyos resultados y conclusiones se publicaron en un libro. El presidente del Colegio Oficial de Arquitectos, uno de los colectivos de profesionales más críticos con el proceso de revitalización de Bilbao, hizo el prólogo de la publicación y definió esta iniciativa como la primera discusión para la transformación de Bilbao con todos los ingredientes. Otros pensaron que este tipo de escenarios sirve para legitimar la política de la institución.

Figura 3. Talleres de participación ciudadana, 2004
Después de este primer debate abierto y propuesto por la ciudadanía, el Gobierno, guiado por el paradigma de la planificación urbana, presentó su megaproyecto de la mano de una arquitecta de renombre. En algunos aspectos fue mejor que lo que temíamos, pues se iban a mantener los edificios residenciales existentes, pero no se incluyeron parques públicos: estaba lleno de rascacielos y, mientras hablaban de sostenibilidad, las únicas acciones reales propuestas eran reciclar el agua de lluvia y desviar el tráfico de la carretera de la ría por el interior de la península. Era un plan $95 \%$ convencional. La pequeña aldea se convertiría en una ciudad de 15.000 habitantes para 2025 .

El Foro siguió adelante, ahora con más ímpetu y con una mayor conciencia de participación de la ciudadanía. A finales de 2004 se organizó un taller de participación ciudadana con la metodología European Awareness Scenario Workshop, que reunió a 59 personas — vecinos, asociaciones, expertos, instituciones gubernamentales y actores económicos - para desarrollar visiones para el futuro de Zorrotzaurre, que luego se debatieron y se votaron. Entre los cinco escenarios más votados estaban "Eco-ciudad", consistente

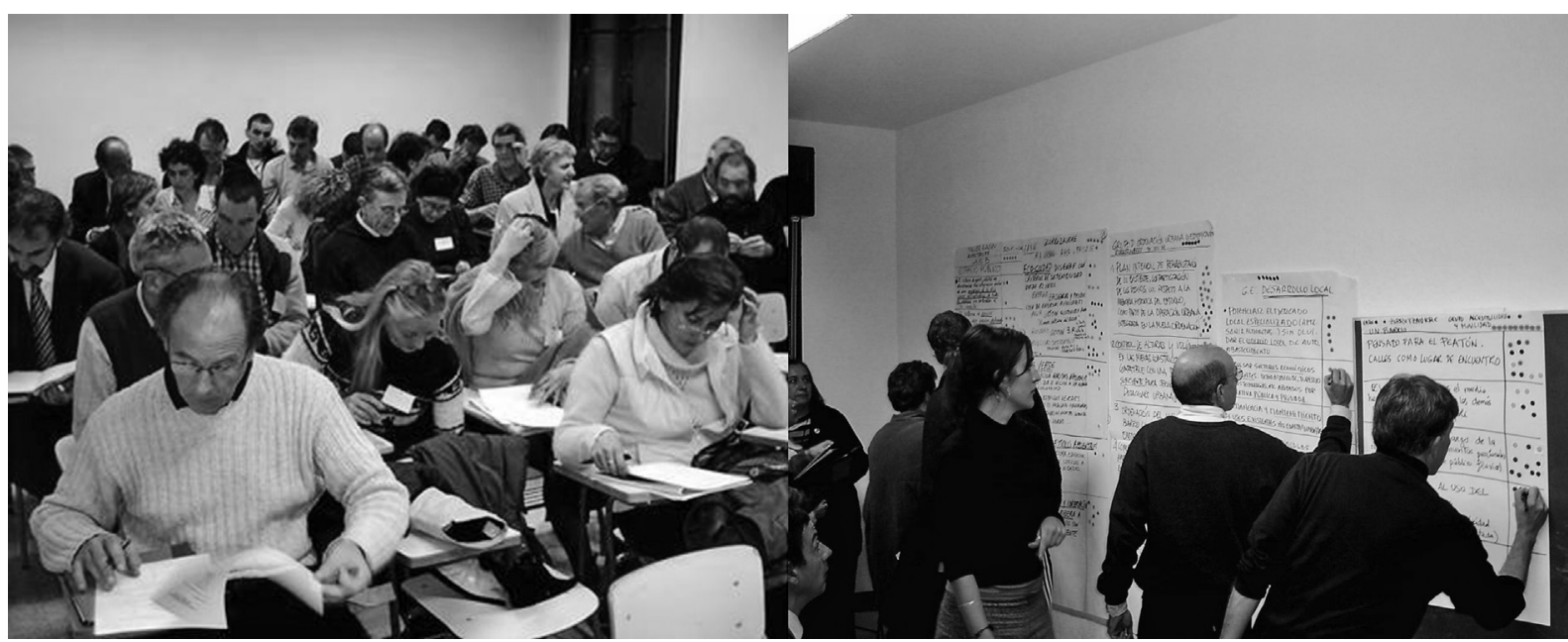

Fuente: archivo de la autora 
en el desarrollo integral de la península con base en criterios ambientales; "Zorrotzaurre verde", que da prioridad al espacio verde y a la regeneración de hábitats naturales y "Barrio pensado para el peatón”. Estas tres ideas juntas, expresan la esencia de un barrio ecológico.

Parecía que el Foro había levantado algunos cimientos en Zorrotzaurre: se abrieron canales de comunicación con las instituciones y los expertos y se había despertado sensibilidad hacia una forma de desarrollo más sostenible. Sin embargo, estos cimientos no serían sólidos mientras la participación ciudadana fuera puntual y excepcional y no se implantara una cultura de participación.

En 2005 y 2006 se organizaron más eventos en el barrio: viajes en barco por la ría, charlas-debate sobre la historia local, la ecología y el patrimonio arquitectónico; la rehabilitación de los edificios existentes y se emprendieron acciones concretas para crear el barrio sostenible: intervenciones en espacio público, taller de permacultura, murales y plantación de árboles y fiesta de diseño urbano (Figura 4).

Figura 4. Mural realizado por los vecinos con el lema "La ribera viva" en 2007

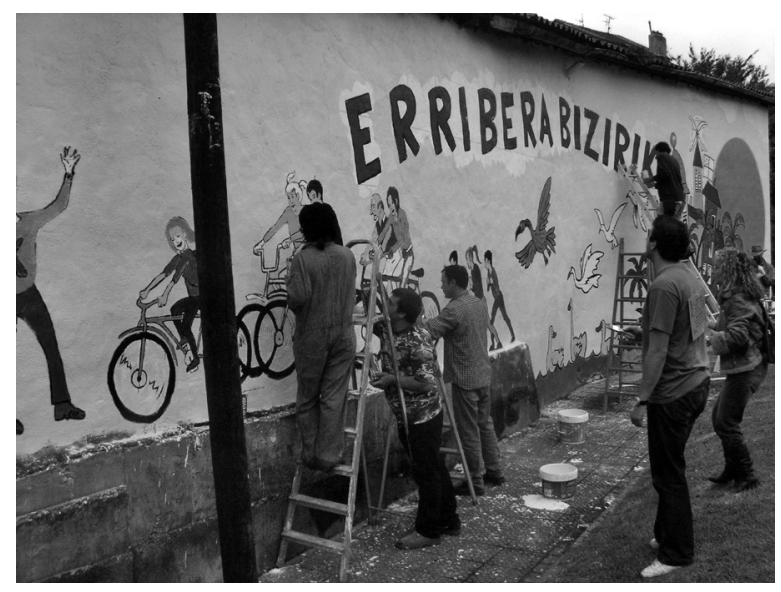

Fuente: archivo de la autora

Las reuniones con las instituciones continuaron y se presentaron las peticiones de los vecinos; se abrieron negociaciones con el Ayuntamiento y con la Comisión gestora para la rehabilitación de las casas; se presentaron alegaciones a la modificación del Plan general de ordenación urbanística; se reforzaron eslabones con las comunidades vecinas que afrontan presiones similares; se creó un sitio web en donde todos pueden contribuir con ideas, información y enlaces y se intercambiaron experiencias con grupos en otras ciudades.

En 2007 Zaha Hadid presentó una modificación al plan inicial de 2004. En este plan, que tuvo un coste final de 1.700.000 euros, se reflejaron algunas ideas propuestas en el Foro: un plan de rehabilitación de viviendas, más espacios verdes, una zona sin coches y peatonalización de la carretera de la ría; sin embargo, se incrementó el número de viviendas para mantener el mismo beneficio económico.

La aprobación definitiva del plan fue en 2012, después de ser contestado por el movimiento vecinal, mediante alegaciones y tribunales. En una resolución judicial hecha pública a finales de marzo de 2010, el Tribunal Superior de Justicia del País Vasco aceptó el recurso presentado por el colectivo vecinal "El Canal" y echó para atrás el Plan de Zorrotzaurre, porque incurría en algunos fallos de procedimiento; el principal era la falta del informe del Consejo Asesor de Planeamiento, con el cual se canaliza la participación de los ciudadanos (Federación de Asociaciones Vecinales de Bilbao, 2010).

Figura 5. Plan aprobado en 2012

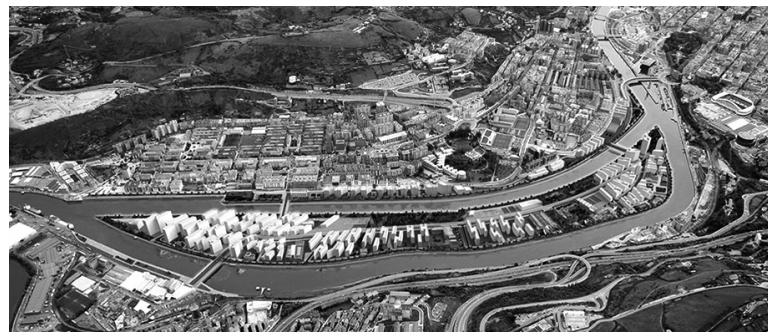

Fuente: Comisión Gestora de Zorrotzaurre (s. f.) 


\section{El aprendizaje como logro de la participación}

El proceso de participación ha proporcionado oportunidades para el aprendizaje social. Las personas tienen la oportunidad de adquirir información y conocimiento, clarificar los propios valores, cultivar la creatividad y proponer nuevas acciones que generen espacios flexibles, resilientes y reciclables como canales para construir diálogos entre lugareńos y actores temporales.

En este análisis hemos identificado que el aprendizaje social adquirido ha dado lugar a espacios de encuentro con nuevos actores y en relaciones de colaboración, pero también de dependencia y conflicto (Figura 6).
El primer espacio que comentamos son las iniciativas culturales. Con cierto apoyo público en algunos casos y desde la iniciativa privada en otros, en algunos de los viejos pabellones y almacenes se han ido instalando gestores culturales que facilitan la revitalización de los espacios en desuso, en el entretanto del proceso urbanístico (Bishop y Williams, 2012). El proyecto ZAWP ha generado oportunidades basadas en la cultura y la innovación con talleres de ukelele, flamenco o jazz. Espacio Open, una iniciativa autogestionada, está implicada de lleno en proyectos de cambio social con la organización de un mercado semanal y la Maker faire ${ }^{3}$ (Figura 7). Pabellón 6 es un colectivo de actores con una forma innovadora de vivir y compartir el teatro, cuyo director cuenta que

Figura 6. Mapa del movimiento social urbano

$\begin{array}{ll} & \text { Identidad local } \\ \text { DETONANTES } & \text { Conciencia de memoria histórica } \\ & \text { Interacción cotidiana } \\ & \text { Cohesión social }\end{array}$

MOVILIZACIÓN

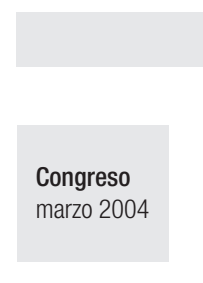

ACTORES

PRODUCTOS

Libro Foro

\author{
Vecinos
}

Instituciones

Informes

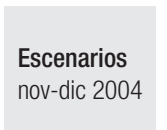

70 pers. Instituciones

Expertos Propietarios

Asociaciones
Talleres y charlas vecinales 2005-6

$100+$ pers Expertos

Vecinos
Estrategia de participación bottom-up

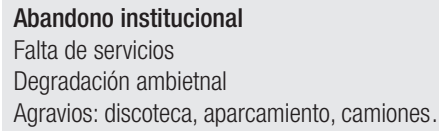

Abandono institucional

Falta de servicios

Degradación ambietnal

Agravios: discoteca, aparcamiento, camiones.

Libro Erribera

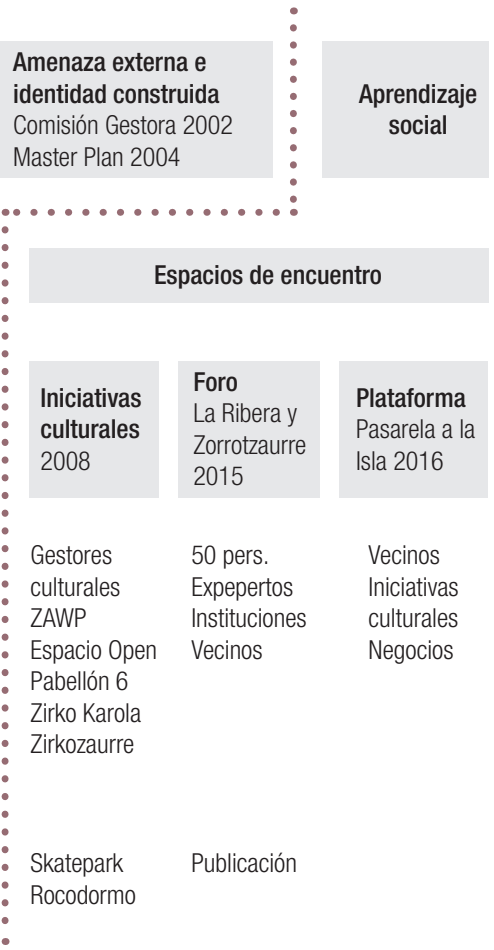

Espacios de debate

Aporte al Master Plan desde experiencia local Conciencia de sostenibilidad

Cultura de participación y aprendizaje social
Ecomonía social

Debate

Nuevas narrativas de transformación

Paso de usuariois a diseñadores y constructores de espacio urbano

Fuente: elaboración propia

3 Es una feria de inventores y creadores, un escaparate de invenciones, creatividad e ingenio pensado para todos los públicos. 
llegó al barrio cuando la ciudad lo había expulsado del centro. Dos pabellones están ocupados por proyectos de circo, Karola Zirko y Zirkozaurre; hay una asociación de quinientos patinadores y un rocódromo de interior (Piugaz).

Oficialmente ya se le denomina la "isla creativa". Algunos consideran que este nombre no es apropiado, pues cuestionan si es más un tema de mercadeo, ya que es mejor hablar de isla creativa que de especulación del suelo (E16, miembro iniciativa cultural teatro, comunicación personal, 20 de junio de 2015). Los gestores de estas iniciativas culturales se encuentran con una normativa rígida que no ayuda a consolidar su establecimiento en el espacio físico, por lo que buscan persuadir al Ayuntamiento para que la flexibilice y puedan consolidar su actividad en el lugar. Para ello están impulsando una economía de base social en la zona (E10, miembro iniciativa cultural ZAWP, comunicación personal, 19 de junio de 2015; E11, miembro iniciativa cultural Espacio Open, comunicación personal, 21 de junio de 2015). Por su parte, la Administración puede ver las prácticas derivadas del aprendizaje social de dos maneras: como una oportunidad para potenciar las prácticas urbanas autogestionadas, es decir, para construir una ciudad participada o bien como un proceso de instrumentalización de las comunidades vivas sobre el territorio para rellenar temporalmente con valor social la desvalorización del suelo. "Se han otorgado permisos, pero han sido temporales por cuestiones de las modificaciones en el territorio" (E8, miembro de la Oficina del Plan general de ordenación urbana, comunicación personal, 30 de abril de 2015).

Las iniciativas creativas se pueden convertir en un elemento facilitador de la tarea de Gobierno, por lo que los gestores independientes deben estar dispuestos a aprovechar esta brecha para presionar a la Administración a hacer cambios más estructurales. Queda claro que el urbanismo del "entretanto" puede ser un caramelo envenenado si no se producen nuevas formas de gestión urbana en los campos jurídico y administrativo.

Por otro lado, la asociación de vecinos ha vuelto a abrir un espacio de debate abierto, un segundo foro para seguir pensando juntos sobre el modelo de ciudad que se está desarrollando. El Foro 2015 fue un reflejo de que la ciudadanía seguía considerándose amenazada por la lógica privatizadora (excesiva edificación, pésima conectividad y el uso de la ciudad creativa como forma de venta del espacio) y este es un elemento motivacional

Figura 7. Prácticas de iniciativas culturales, ZAWP y Espacio open

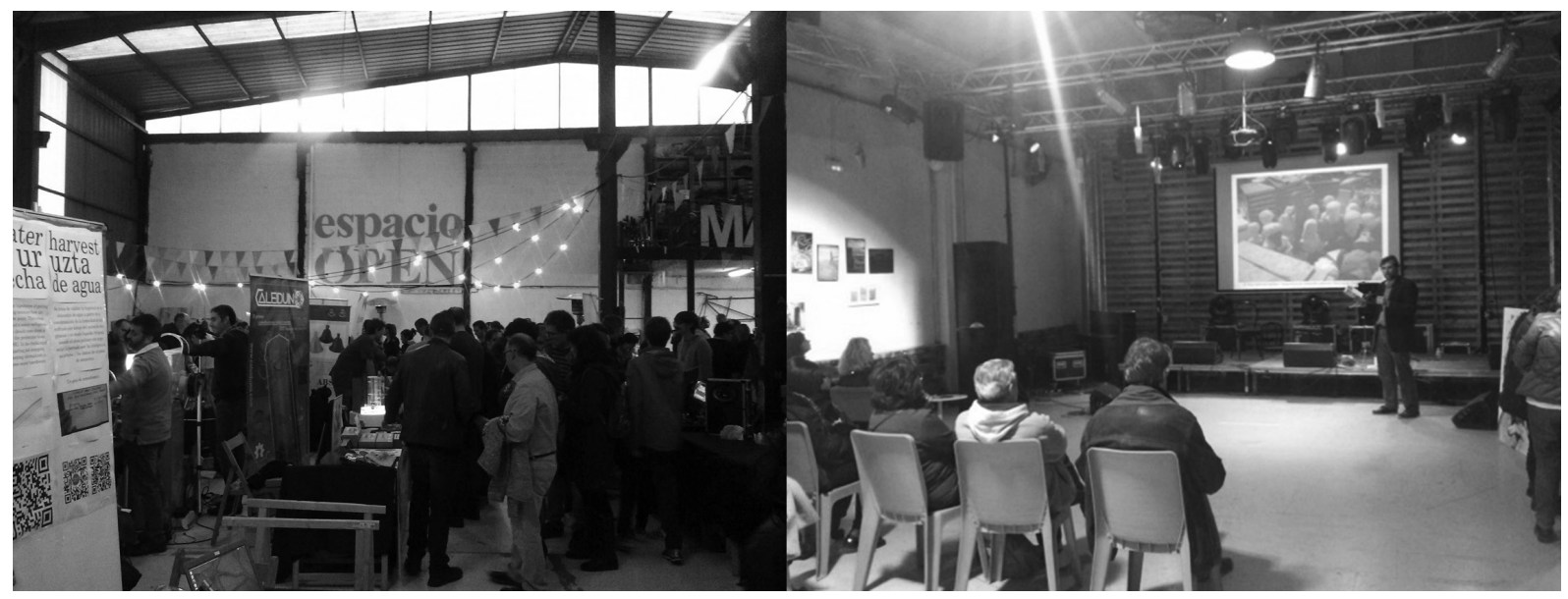

Fuente: elaboración propia 
para mantener las prácticas participativas y comunales. Sin embargo, las perspectivas de crear un barrio sostenible han ido disminuyendo, al aceptar el Máster Plan como el instrumento de planificación. Se han asumido las transformaciones del capitalismo actual (Scott, 2001), puestas de manifiesto en las planificaciones urbanas y las dinámicas resultantes, en especial en los barrios posindustriales o de oportunidad.

Algunos vecinos consideran que sus espacios están siendo ocupados con la aparición de las iniciativas culturales que han emergido en el entretanto. Denuncian que estas iniciativas culturales son negocios subvencionados por la institución pública y manifiestan la existencia de una "gentrificación lenta y amable del barrio" (Asociación de Vecinos Euskaldunako Zubia, 2015, p. 27). Este enfrentamiento entre algunos vecinos y gestores independientes no es generalizado, pero ha creado una disrupción leve en el movimiento social urbano y pérdida de influencia en la planificación urbana. Los actores del movimiento social urbano debemos tener en cuenta que hace falta un movimiento suficientemente fuerte como para negociar con la Administración.

La pérdida de identidad es un tema recurrente durante todo el proceso de participación. La aparición de nuevas experiencias hace que la identidad de la gente se vea forzada a enfrentarse a la negociación de prácticas sociales de un espacio y tiempo. La experiencia de estas prácticas nos indica que solo podremos acercarnos si abrimos la frontera de la identidad y creamos zonas de hibridación o negociación, en donde surja la capacidad para ser otro y aceptarlo. Por lo tanto, estos espacios de encuentro o las espacialidades de emancipación deben ser considerados como procesos formativos de prácticas sociales que marcan transformaciones en la identidad social (Stavrides, 2016).
Necesitamos una identidad abierta con fronteras flexibles que ofrezcan puntos de encuentro para prácticas sociales. Estos espacios pueden ser escenarios de aprendizaje social que marquen transformaciones en la identidad social y en el espacio. Un buen ejemplo de ellos es la Plataforma Pasarela, creada en octubre de 2016. Con el inicio de la apertura del canal de Deusto en 2015 y el cierre de la conexión natural del barrio con el resto de Bilbao, el paseo a lo largo de la ría, los vecinos, los gestores de iniciativas culturales y los negocios locales se ven más alejados del resto de la ciudad. "Nos han dejado aislados; yo voy menos andando y la gente viene menos a la ribera" (E8, vecina de la ribera, comunicación personal, 24 de marzo de 2015). "Es muy difícil que la gente llegue al barrio si no es con su propio coche y luego se crean problemas de aparcamiento" (E10, miembro de la iniciativa cultural ZAWP, comunicación personal, 21 de marzo de 2015). Este descontento, unido a un aprendizaje social, ha activado de nuevo un movimiento ciudadano bottom up que reivindica la conectividad sostenible: una pasarela para peatones y bicicletas que continúe el paseo que existió.

Estas prácticas propugnan por un cambio de modelo urbano lejos del expansionismo especulativo de las últimas décadas, orientado a la regeneración y reapropiación de la ciudad. El urbanismo formal, a menudo criticado por lento y rígido, se ha visto alterado por iniciativas que cambian el rol de los residentes, que pasan de ser meros usuarios a diseñadores y constructores del espacio público. Se vislumbra una cultura participativa en un movimiento social organizado.

\section{Resumen de los resultados del proceso} participativo

Los procesos de participación efectiva ciudadana son escasos, complejos y difíciles de analizar; sin 
embargo, este caso de estudio tiene una serie de impactos físicos, económicos y sociales visibles que listamos a continuación:

- Mantenimiento y rehabilitación de viviendas con un plan integral y financiación

- Modificaciones concretas del Máster Plan, sobre todo en cuanto al espacio público. Reducción de tráfico, zonas sin coches, más espacio verde.

- Adopción de "sostenibilidad" como lema para la planificación del barrio.

- Iniciativas de economía local que dinamizan y crean empleo, nuevos espacios y otra imagen de ciudad.

- Apertura de canales de diálogo. Más relación y confianza entre la Administración, los gestores y los vecinos. Establecimiento de contactos con expertos y otras entidades como universidades.

- Mayor capital social por medio de la mejora del conocimiento local y de la cultura de participación. Se ha desarrollado una conciencia sobre la importancia de la participación ciudadana entre el vecindario y la administración local.

\section{Discusión de resultados: lecciones aprendidas del proceso de participación}

La evaluación de este proceso de participación invita a reflexionar sobre el papel de la ciudadanía en el espacio público y en la creación de ciudades más habitables. Examinamos dos cuestiones clave sobre la participación y cuáles serían los ingredientes para que esta sea efectiva. La primera cuestión está relacionada con los detonantes del movimiento social y por qué surgen en un barrio periférico de carácter obrero que congrega vectores estructurales de abandono. La siguiente cuestión abre el debate sobre el protagonismo de la participación en la gestión de la ciudad.

\section{Detonantes}

El caso de estudio muestra que en la ribera se comparte una memoria histórica colectiva que comprende los cambios producidos en la morfología social y arquitectónica de la zona a lo largo del siglo XX.

Por otro lado, la interacción cotidiana entre los residentes ha propiciado redes sociales como espacios de acción social que se han ido consolidando con una fuerte cohesión social. Estas características definen la identidad local y el sentimiento de pertenencia. A esta identidad se une la sensación de abandono por parte de la institución en los últimos treinta años: falta de servicios e infraestructuras, degradación ambiental y agravios como prácticas del botellón y actos vandálicos. A ello se suma la amenaza externa: un modelo de urbanismo neoliberal que impone otra identidad, otra forma de ver el barrio. Todo esto genera una movilización y una ciudadanía que se sintió capaz de juzgar acontecimientos y debatir, como acto preliminar a la forma de cualquier decisión sabia.

\section{Participación en la gestión pública}

\section{Participación consultiva}

En este apartado analizaremos la efectividad de la participación mediante entrevistas semiestructuradas. El proceso de participación fue propuesto por los vecinos, quienes querían participar en el diseño de su barrio y demandaron el derecho a la ciudad. "Propusimos un espacio de debate en el que encontramos y dialogamos con expertos y ciudadanos y generamos ideas y argumentos dentro de un marco de trabajo compartido, con 
la prospectiva como instrumento" (E3, cofundador del Foro para un Zorrotzaurre sostenible, comunicación personal, 12 de marzo de 2015).

El Máster Plan tuvo críticas por parte de profesionales y ciudadanía, porque la Administración no convocó un debate previo con la opinión pública. Resulta obligatorio que los planes urbanísticos de cualquier magnitud sean objeto de un proceso de participación reglado de abajo a arriba, en lugar de presentar una exposición del diseño final (Allende, 2005). Los agentes sociales consideraron que a los políticos no les terminaba de convencer la participación de los ciudadanos; además, no tenían la experiencia ni el conocimiento en cuanto a las implicaciones de otros actores en la definición del espacio público (E9, miembro de la Federación de Asociaciones Vecinales de Bilbao, comunicación personal, 21 de marzo de 2015).

Los agentes privados percibieron que la participación de los vecinos era reactiva, ya que solo apuntaban a defender sus intereses particulares; las acciones realizadas habían sido investidas de criterios de sostenibilidad y, una vez conseguidos los beneficios particulares, los criterios de sostenibilidad perdían fuerza (E4, miembro de la Comisión Gestora de Zorrotzaurre, comunicación personal, 11 de marzo de 2015).

"No existe un dialogo razonado entre las partes y se necesitan interlocutores con sensibilidad y formados para traducir insensibilidades de la realidad y cómo se deben de compensar todos los sacrificios" (E4, experto en movilidad y accesibilidad urbana, comunicación personal, 25 de junio de 2015). Por tanto, la capacidad decisoria real y legal del movimiento social Foro para un Zorrotzaurre sostenible es muy reducida.

El único mecanismo formal de intervención en la planificación urbana son las alegaciones que se han presentado durante la ejecución de los planes. No hay una teoría política que legitime a los actores sociales cuando estos no han sido elegidos por cauces formales. Formamos parte de una democracia representativa y eso da lugar a una gran desigualdad de poder entre actores. El poder de decisiones está delegado a este organismo del que la ciudadanía no forma parte, un partenariado público-privado. Poco a poco, esto va provocando desconfianza en el sistema de representación formal, lo que produce desinterés progresivo de la ciudadanía en el sistema político y en su espacio vital. El poder de decisión de la ciudadanía se sitúa en el nivel intermedio o participación simbólica (Arnstein, 1969); la comunidad recibe información acerca de los propósitos de los agentes de desarrollo en relación con las acciones que desean llevar a cabo y aquella proporciona información.

Se abrió un espacio de debate en donde los miembros de la comunidad proponían ideas o sugerencias, pero no había obligatoriedad de incorporarlas a una política o un plan final. No se delega una cuota de poder por parte de la Administración en un organismo en el cual exista una mayoría ciudadana que ejerza control, por lo que se puede hablar de pseudoparticipación (Pateman, 1970). La construcción del espacio siempre es una lucha de poderes (Lefebvre, 1974) y lo ocurrido es un ejemplo de la aplicación de modelos unidimensionales, que responden a una concepción tecnocrática de la participación social, en la que el planificador defina las necesidades de una forma científica y eluda la participación ciudadana en la toma de decisiones en materia urbanística (Martínez, 2011). La democracia participativa no parece ser una prioridad; se tiende más a reproducir una estructura jerárquica de poder.

\section{Conclusiones y propuesta}

Este movimiento social propone una regeneración sostenible desde lo local y demuestra 
que la demanda de participación ciudadana sigue vigente; una demanda que saca a la luz una cuestión de fondo: la incompatibilidad de la democracia, de la participación real y deliberativa y de la ciudadanía efectiva, con el urbanismo empresarial. La estrategia de participación bottom up fue efectiva, pues permitió integrar una visión sistémica al incorporar en el debate a diversos actores y adelantar el proceso de forma estructurada por medio de foros, debate, talleres, votación de propuestas y consensos.

La participación fue de carácter informativo y consultivo, dado que en ningún caso la Administración previó la creación de espacios de poder deliberativos para la ciudadanía. Como dice David Harvey (2013), "la urbanización capitalista tiende perpetuamente a destruir la ciudad como bien común social, político y vital" (p. 125). La clase política y la clase capitalista, que van de la mano en la gestión de las políticas municipales, dominan el proceso urbano, los aparatos del Estado y nuestras vidas cotidianas; por ello, la ciudad y los procesos urbanos son importantes focos de lucha política, social y de clase. Es tarea de los movimientos sociales urbanos de base vecinal enfrentarse a estas dinámicas, reclamar el derecho a la ciudad y construir la ciudad y su propia vida.

La movilización social tuvo impacto físico, económico y social. Se insertaron modificaciones en el Máster Plan; se ampliaron los espacios verdes y se redujo el tráfico rodado; se han mantenido y rehabilitado las viviendas; se aportó conocimiento local al debate sobre la planificación del barrio; se plantearon propuestas pensadas desde las propias vivencias y se incorporó un gran número de visiones y sensibilidades para aumentar la efectividad de la participación y evitar conflictos posteriores. Sobre todo, el proceso ha servido para desarrollar un aprendizaje social que ha abierto nuevos espacios de encuentro e incentiva a la ciudadanía a diseñar su propia vida, tras reforzar el compromiso por el bien común. Estos nuevos espacios (las iniciativas culturales, el debate-foro diez años después del Máster Plan y la Plataforma Pasarela) se han convertido en mecanismos de democracia directa para que la participación ciudadana se inserte en procesos de planificación-gestión urbana. Estos aparecen desde la dimensión ciudadana como seña de identidad de los movimientos sociales actuales.

- Vamos construyendo la ciudad proactiva. Esta propuesta recupera las lecciones aprendidas del caso de estudio y recoge las directrices de un proceso de participación acción que puede ser aplicado en otros contextos. Para construir una ciudad proactiva necesitamos una ciudadanía que cree redes, consiga alianzas transversales con líderes y expertos motivados que trabajen en equipo y esté comprometida con la defensa del bien común. Al mismo tiempo, se requiere una institución abierta que modifique reglamentos para favorecer una participación más democrática, que conceda derecho a voto y carácter vinculante a las decisiones adoptadas y atribuya poder a los ciudadanos. Así se genera un aprendizaje social y espacios flexibles, resilientes y reciclables que no dependen de la experimentación institucional, sino que suponen cambios en los modos de hacer de la propia Administración. Por último se precisan narrativas transformadoras. Hay que contar la relación entre procesos sociales y espacios de forma compartida, para que pueda ser asumida y la sociedad cambie de verdad. Las historias son de vital importancia, aunque tenemos una escasez enorme de historias acerca de cómo avanzar creativamente y de historias que nos contamos a nosotros mismos.

Esta metodología nos permite pasar de planificar las ciudades por megaproyectos a formas fundamentadas en la construcción de movimientos. Esto implica proyectar un modelo de ciudad basado en investigaciones participativas y procesos 
Figura 8. Propuesta de metodología hacia la construcción de la ciudad proactiva

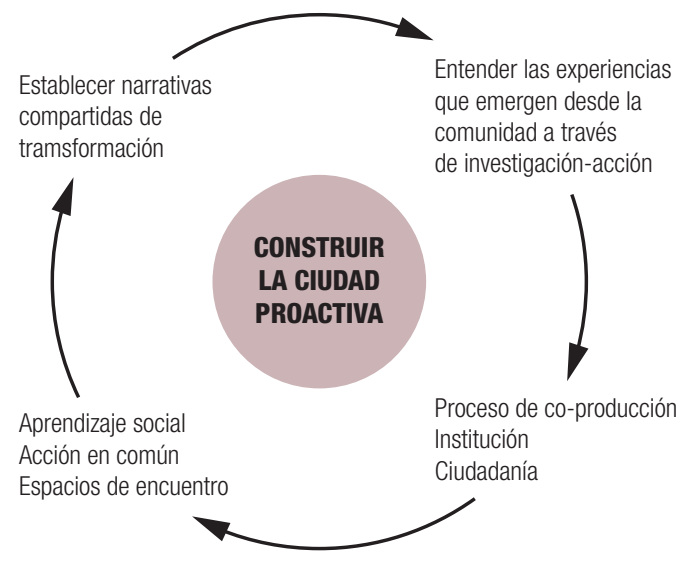

Fuente: elaboración propia

de coproducción ciudadanía-institución (colaboración público-privada) que responda a las prioridades y aspiraciones que emergen de las comunidades locales, amplificar las iniciativas locales existentes y conectarlas con los nuevos proyectos en un mismo movimiento que refleje el sistema de valores y las narrativas del barrio y de la ciudad. Así aparecerán nuevas plataformas de acción colectiva, con narrativas compartidas de transformación.

Zorrotzaurre, paisaje industrial, urbano y humano, con su participación ciudadana y sus fábricas creativas, es ya una ciudad improvisada en donde surgen prácticas, acciones y comportamientos que, al margen de los usos tradicionales del espacio y sin respetar las reglas establecidas, propone formas nuevas de relacionarse con el territorio y aprovechar el recurso "ciudad". La creación y el uso social de esos lugares de encuentro potencian el urbanismo emergente: la ciudad proactiva. Experimentar y conceptualizar nuevas metodologías y herramientas de participación contribuye a construir unas relaciones sociales distintas y dar forma a los mundos sociales posibles, capaces de inspirar acciones y expresar sueños colectivos.
El Máster Plan de Zaha Hadid apareció en un contexto de bonanza que ha cambiado radicalmente con la crisis financiera de 2008 y con el cambio climático. Hay que plantearse otro modelo de ciudad que arregle las variables que construyen ciudades resilientes, con equidad. Zorrotzaurre se convierte en el laboratorio donde se van a llevar a cabo experimentos para determinar el rumbo del Gran Bilbao, después de la época del efecto Guggenheim. Entender las experiencias que emergen de los valores y las aspiraciones de la comunidad, ejecutar acciones conjuntas y establecer narrativas compartidas nos conducen a desarrollar movimientos que guíen este cambio de paradigma urbanístico.

\section{Agradecimientos}

El artículo presenta los resultados de la investigación "La participación en el urbanismo, clave para la sostenibilidad urbana". Entidad financiadora: Universidad de Deusto. Fecha de inicio: septiembre de 2013. Fecha de finalización: junio de 2016. Grupo de investigación: Desarrollo humano. Instituto de Ocio.

\section{Bibliografía}

Asociación de Vecinos Euskaldunako Zubia. (2015). ¿La Ribera vs Zorrotzaurre? 10 años después del Máster Plan. Bilbao: Autor.

Allende, J. (2005, enero 4). Zorrotzaurre: urbanismo de maqueta. El País. Recuperado de https://elpais.com/diario/2005/01/04/paisvasco/1104871203_850215.html

Ansell, C. y Gash, A. (2008). Collaborative Governance in Theory and Practice. Journal of 
Public Administration Research and Theory, 18(4), 543-571.

Areso, I. (2016, junio 20-julio 1). Urbanismo y planificación de Bilbao. Conferencia presentada en el IX Curso en planificación y gestión de ciudades. Bilbao: Universidad de Deusto.

Arnstein, S. R. (1969). A Ladder of Citizen Participation. Journal of the American Institute of Planners, 35(4), 216-224.

Ashworth, G. J. y Voogd, H. (1990). Selling the City. Londres: Belhaven Press.

Bishop, P. y Williams, L. (2012). The Temporary City. Londres: Routledge.

Borja, J. (2012). Espacio público y derecho a la ciudad. Recuperado de https://debatstreballsocial. files.wordpress.com/2013/03/espacio_publico_ derecho_ciudad_jordiborja.pdf

Comisión Gestora de Zorrotzaurre. (s. f.). San Ignacio. Recuperado de http://www.zorrotzaurre.com/wp-content/uploads/al_gallery_ files/ai_photo_files/al_photo_thumb_files/ Zorrotzaurre-Puente-San-Ignacio-Zorrotzaurre9-thumb.jpg

Esteban, M. (2000). Bilbao, luces y sombras del titanio: El proceso de regeneración del Bilbao metropolitano. Bilbao: Universidad del País Vasco.

Federación de Asociaciones Vecinales de Bilbao.

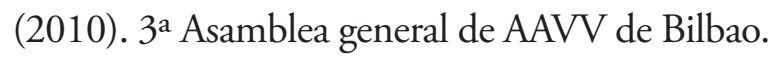
Hiritarrok (7). Recuperado de http://www.bakarra. net/cms/media/Hiritarrok_7_EXTRA.pdf

Forester, J. (1988). Planning in the Face of Power. Berkeley: University of California Press.

Gehl, J. (2010). Cities for People. Washington: Island Press.
Giddens, A. (1984). The Constitution of Society: Outline of the Theory of Structuration. Los Ángeles: University of California Press.

Girardet, H. (1999). Creating Sustainable Cities. Foxhole: Green Books.

Habermas, J. (1989). Teoría de la acción comunicativa. Buenos Aires: Taurus.

Harvey, D. (1989). Capitalism from Managerialism to Entrepreneurialism in Urban Governance Transformation. Geografiska Annaler, 71(1), 3-17.

Harvey, D. (2013). Ciudades rebeldes. Del derecho a la ciudad a la revolución urbana. Madrid: Akal.

Healey, P. (1997). Collaborative Planning: Shaping Places in Fragmented Societies. Basingstoke: Palgrave Macmillan.

Healey, P. (2006). Urban Complexity and Spatial Strategies: Towards a Relational Planning for our Times. Nueva York: Routledge.

Innes, J. E. (1995). Planning Theory's Emerging Paradigm: Communicative Action and Interactive Practice. Journal of Planning Education and Research, 14(3), 183-189.

Jacobs, J. (1961). The Death and Life of Great American Cities. Nueva York: Vintage Books.

Klein, N. (2015). This Changes Everything: Capitalism vs. the Climate. Toronto: Vintage Canada.

Lefebvre, H. (1969). El derecho a la ciudad. Barcelona: Península.

Lefebvre, H. (1974). La producción del espacio. Papers (3), 219-229.

Martínez, M. (2011). Dimensiones múltiples de la participación ciudadana en la planificación 
espacial. Revista española de investigaciones sociológicas (133), 21-42.

Mazin. (2001). Un barrio genial. Makala, (3), 19.

Pateman, C. (1970). Participation and Democratic Theory. Nueva York: Cambridge University Press.

Pindado, F. (2005). La participación no se improvisa. Revista de estudios locales (87). Recuperado de http://www.famp.es/export/sites/famp/.galleries/documentos-obs-participacion/La_participacion_no_se_improvisa_-_Fernando_Pindado.pdf

Rodríguez, A., Vicario, L., y Martínez, E. (2005). Competitividad y urbanismo "creativo" en la revitalización de Bilbao: entre la necesidad y la especulación. Bilbao: Universidad del País Vasco.
Sassen, S. (2000). Cities in a World Economy. Thousand Oaks: Pine Forge.

Scott, A. J. (ed.) (2001). Global-City Regions. Oxford: Oxford University Press.

Soja, W. (2008). Postmetrópolis: estudios críticos sobre las ciudades y las regiones. Madrid: Traficantes de sueños.

Stavrides, S. (2016). Hacia la ciudad de umbrales. Barcelona: Akal.

Zukin, S. (1988). The Postmodern Debate over Urban Form. Theory, Culture \& Society, 5(2), 431-446.

Zukin, S. (1989). Loft Living: Culture and Capital in Urban Change. Londres: The Johns Hopkins University Press. 